\title{
Teaching Reformation and Innovation of Pharmaceutics Experiment of Pharmacy Major
}

\author{
Wufu ZHU ${ }^{1, a^{*}}$, Shan XU ${ }^{1, b^{*}}$, Qidong Tang ${ }^{1, c}$ and Pengwu Zheng ${ }^{1, d}$ \\ ${ }^{1}$ School of Pharmacy, Jiangxi Science \& Technology Normal University, Nanchang 330013, China \\ azhuwufu-1122@163.com, ${ }^{b}$ shanxu9891@126.com, ctangqidongcn@126.com, ${ }^{\mathrm{d}}$ zhengpw@126.com \\ ${ }^{*}$ corresponding author
}

Keywords: Pharmaceutics Experiment; Reformation and Innovation; Teaching experience; Education; Experimental Teaching

\begin{abstract}
Pharmaceutics experiment is an important curriculum which acts as a bridge between medicine science, pharmacy theories and practice. In order to improve the teaching effect of experiment of pharmaceutics, this article discusses the characteristic of pharmaceutics experiment and told how to put the teaching reform into practice. Two methods including traditional way and new method were applied in this project. After one years' practice, four groups exhibit different ability in Pharmaceutics Experiment. The results showed that the new method can improve the manipulative ability and learning ability in pharmaceutical course of the undergraduate students.
\end{abstract}

\section{Introduction}

Pharmaceutics is the discipline of pharmacy that deals with the process of turning a new chemical entity (NCE) or old drugs into a medication to be used safely and effectively by patients, and is also the study of relationships between drug formulation, delivery, disposition and clinical response. .There are many chemicals with pharmacological properties, but need special measures to help them achieve therapeutically relevant amounts at their sites of action. Pharmaceutics deals with the formulation of a pure drug substance into a dosage form. Branches of pharmaceutics include: pharmaceutical formulation, pharmaceutical manufacturing, pharmaceutical technology, and so on [1-4].

Pharmaceutics experiment is an important practice course after learning the course of pharmaceutics. Through pharmaceutics experiment, the pharmacy theories and the skills of practice of the undergraduate students can better understand and improved. Therefore, pharmaceutics experiment is a very important course for the students of the Pharmacy and other related majors.

However, most universities in China paid little attention on the experiment courses and practice courses, even some " 985 " and " 211 " Pharmaceutical universities, such as the China Pharmaceutical University and Shenyang Pharmaceutical University. Some schools think that those courses are less important than the pharmacy theories courses. Therefore, some of these courses are canceled in some pharmacy college [5-7].

What's more, even the experiment courses are set in those universities, most of the universities, the corresponding teachers and the students treat those classes with regardless. And most of the experiment or practice classes are tasteless for the teachers teaching in the traditional way which can often see in the class. The traditional way for experiment and practice courses is that the teacher firstly teaching the methods for the experiment and than the students finished the experiment according to the operation. In the traditional way, students have no time to think of "WHAT, HOW AND WHY" about the experiment, and just follow to the teachers and finish the assignment. Students learn very little in those class and most of them hate these class. The effect of class is also bad [8-14].

The chart 1 shows the current state for most of the experiment or practice courses in the pharmacy universities in China. The results show that $90 \%$ of the experiment courses are carried out through the traditional way. 


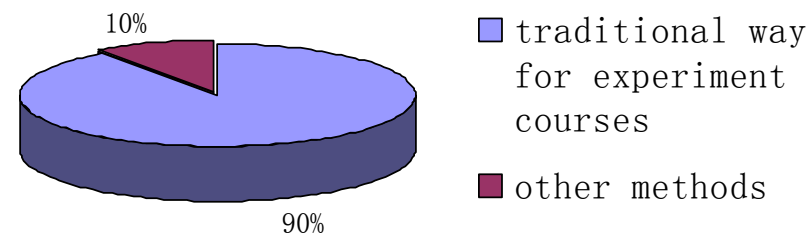

Chart 1 current state of teaching way of the experiment or practice courses in the pharmacy universities

Here, in this paper, we introduce one new method for experiment courses for undergraduate in School of Pharmacy, Jiangxi Science \& Technology Normal University. And the advantage and disadvantage for the method is discussed.

\section{Methods}

We choose one class of Pharmacy major as subjects. The whole class is divided into four groups, group 1-4. And any two of them (group 1 and 2) were choose as the references groups using traditional teaching methods. The other two groups (group 3 and 4) were choose as experiment groups using the new teaching methods.

For different groups, we chose different way for experiment courses. Table 1 shows the difference for these two methods.

Table 1 the difference between traditional and new methods for experiment courses in this project

\begin{tabular}{|c|c|c|}
\hline Methods & Traditional method & New method \\
\hline Book & Traditional experiment book & New designed experiment book by teacher \\
\hline Teaching way & Traditional way & $\begin{array}{l}\text { Not only the traditional way, but also } \\
\text { practice in Lab and pharmaceutical factory }\end{array}$ \\
\hline Practice way & Follow the teacher & Finished by themselves \\
\hline Discussions & No discussions & Several times for each experiment \\
\hline Exercise & No exercise & Exercise for each class \\
\hline Examinations & $\begin{array}{l}\text { No examinations, just } \\
\text { according to the experiments } \\
\text { reports }\end{array}$ & $\begin{array}{c}\text { Taking an exam by doing any of the } \\
\text { experiment }\end{array}$ \\
\hline
\end{tabular}

\section{Results}

After one year later, the new method was applied in this class. Some tests were carried out to evaluated whether the new method have some advantages to the traditional way.

Firstly, the finally scores for the new methods (groups 3 and 4) are much better then that of the traditional way groups (groups 1 and 2). The results showed in table 2.we can easily find that the mean scores are much higher for the new methods (groups 3 and 4). 
Table 2 the mean finally exam scores by using different teaching methods

\begin{tabular}{clll}
\hline $\begin{array}{c}\text { Group } \\
\text { /Methods }\end{array}$ & Traditional method & New method & Mean scores for exam \\
\hline Group 1 & $\sqrt{ }$ & - & $80-85$ \\
Group 2 & $\sqrt{ }$ & - & $82-86$ \\
Group 3 & - & $\sqrt{ }$ & $88-90$ \\
Group 4 & - & $\sqrt{ }$ & $87-92$ \\
\hline
\end{tabular}

Secondly, the students are more satisfied with the new methods while most of the students don't want to attend the traditional experiment classes. The results were shown in chart 2 . We think that diversified forms of the classes of the new method resulted in the different effect of these two method. The results also suggested that the new method have many advantages.

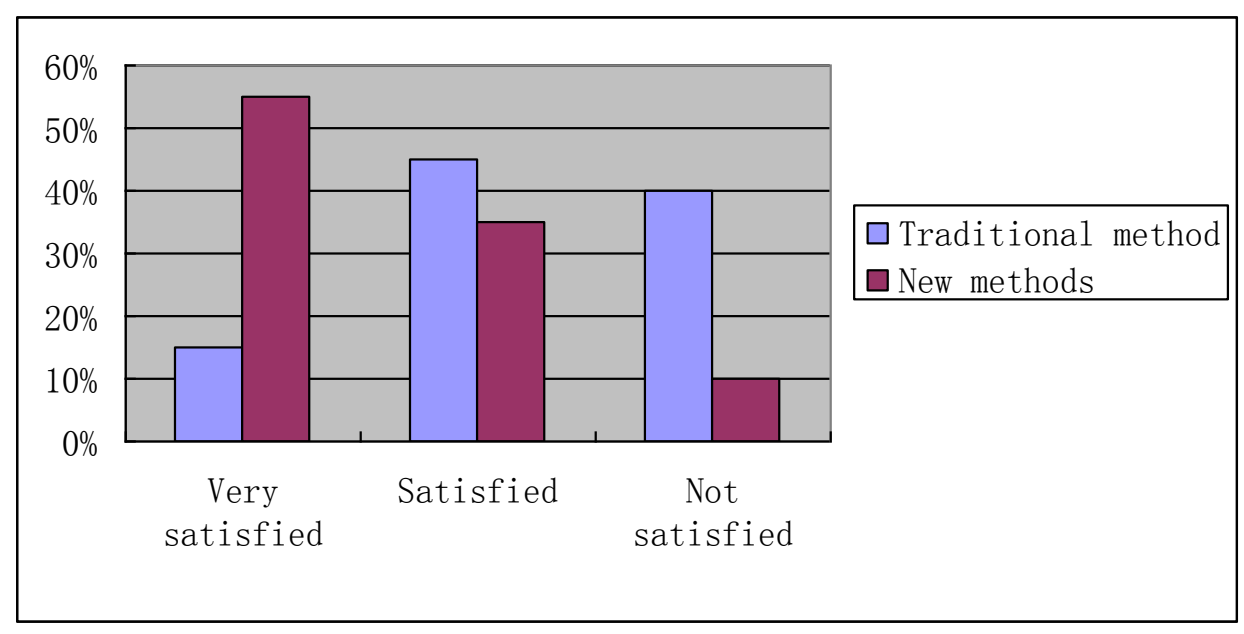

Chart 2 Results of the students attitude toward the two methods.

Thirdly, the skill of the students teaching by the new methods improved a lot and is much better than that teaching by the traditional methods.

\section{Summary}

In this paper, we discussed the traditional way for teaching pharmaceutics experiment and a new method was established in this project. Then, this project was carried out for a year. The results shown that the new method have many advantages, such as higher exam scores, much more popular to the students and the skills of the students can improve a lot, and the new method can improve the manipulative ability and learning ability in pharmaceutical course of the undergraduate students.

\section{Acknowledgments}

We gratefully acknowledge the generous support provided by the higher education educational reform research project of Jiangxi Province (JXJG-13-10-19) and higher education educational reform 
research project of Jiangxi Science \& Technology Normal University (JGZD-13-10-9\& JGYB-14-24-18)

\section{References}

[1] Hu R. Applying Creative Thinking to Guide Reform on Experiment Teaching of Pharmaceutics of TCM, J. Lishizhen Medicine and Materia Medica Research, 2007, 8.

[2] Gwilt P R. A Student Experiment in Pharmaceutics: Saliva Concentrations of Acetaminophen, J. American Journal of Pharmaceutical Education, 2, 43(1979) 124-26.

[3] Zhao, Guang-rong, et al. Education of Pharmaceutical Engineering in the United States of America, J. Pharmaceutical Education, 1(2005) 019.

[4] Deng, Chao, et al. Exploration of Pharmaceutics Talent Education Mode for the Enterprise-University-Research Cooperation., J. Pharmaceutical Education, 4 (2012) 005.

[5] Ding X, Lu Y, Ding B, et al. Teaching Experience on Designing Experiment of Pharmaceutics , J. Research and Exploration in Laboratory, 6(2011) 090.

[6] Zhang, X, Wang S.Reforming Experimental Teaching All-roundly to Cultivate Students' Innovative Abilities , J. Research and Exploration in Laboratory , 1(2005) 4-6.

[7] Deng, Li, et al. Personal Experience and Practice in Teaching Reform on Pharmaceutics, J. Pharmaceutical Education, 4 (2007) 012.

[8] Chang, C, Lu N. The Problem of Experimental Teaching and Its Reforming Measures, J. Research and Exploration in Laboratory , 2(2006) 033.

[9] Cheng, J, Wu B, Jin X, and Huang Z. Reformation and Practice of the Experimental Teaching Examination Model in Universities, J. Research and Exploration in Laboratory, 4(2005) 027.

[10] Galvao, Tais F., et al. Problem-Based Learning in Pharmaceutical Education: A Systematic Review and Meta-Analysis, J. The Scientific World Journal, 2014 (2014).

[11]Huang, Qiu jie, and Yong Ye. Discussion on the Teaching of Pharmaceutics, J. Guangzhou Chemical Industry, 1 (2013) 081.

[12] Yu, F. A. N. Exploration of Application-oriented Diverse Teaching Mode for Pharmaceutics Teaching Reform, J. Journal of Anhui Agricultural Sciences, 31 (2014) 134.

[13]Chen, Jing xiao, et al. The Application of PBL Pattern in Innovated Teaching of Pharmaceutics , J. Guangzhou Chemical Industry, 2 (2013) 054.

[14] Wang, Ying zi, et al. Reform in experimental teaching of Chinese medicinal pharmaceutics based on CDIO teaching idea, J. Education of Chinese Medicine, 4 (2013) 006. 